\title{
Bayesian network revealing pathways to workplace innovation and career satisfaction in the public service
}

\author{
Warit Wipulanusat (iD) ${ }^{\mathrm{a}}$, Kriengsak Panuwatwanich (D) ${ }^{\mathrm{b}}$, Rodney A. Stewart (DD ${ }^{\mathrm{c} *}$, \\ Stewart L. Arnold (D) $^{\mathrm{d}}$ and Jue Wang (D) $^{\mathrm{e}}$
}

${ }^{a}$ Logistics and Business Analytics Center of Excellence and School of Engineering and Technology, Walailak University, Nakhonsithammarat, Thailand

${ }^{b}$ School of Civil Engineering and Technology, Sirindhorn International Institute of

Technology, Thammasat University, Pathum Thani, Thailand

${ }^{c}$ School of Engineering and Built Environment, Griffith University, Queensland, Australia

${ }^{d}$ Nanyang Business School, Nanyang Technological University, Singapore

${ }^{e}$ School of Social Sciences, Nanyang Technological University, Singapore

*corresponding author: Rodney A. Stewart

School of Engineering and Built Environment, Griffith University, Southport, Queensland 4222, Australia

email: r.stewart@griffith.edu.au 


\section{Bayesian network revealing pathways to workplace innovation and career satisfaction in the public service}

This paper examined the innovation process in the Australian Public Service (APS) using a Bayesian network (BN) founded on an empirically derived structural equation model. The focus of the BN was to examine the impact of leadership style and organisational culture on workplace innovation and career satisfaction in the APS. Using scenario analysis, the best combination of managerial actions for enhancing APS career satisfaction was determined. The results emphasise the benefit of encouraging management to adopt a transformational leadership style and instilling innovative culture in their organisation. In addition, innovative culture was a key driver of workplace innovation, which served to improve the career satisfaction of APS employees. Implications are discussed to propose practical strategies for organisations wish to encourage innovation among employees.

Keywords: innovation; public sectors; scenario analysis; Bayesian network; structural equation model.

\section{Introduction}

Public sector innovation has been brought into scholarly attention since the 1970s and was a theme often mentioned in literature on New Public Management (Pollitt \& Bouckaert, 2011), e-government (Bekkers \& Homburg, 2005), and smart government (Gil-Garcia, Helbig, \& Ojo, 2014). In the 1990s, public managers started to put innovation into practice (Bason, 2010) as they realized that innovation could help to enhance problem-solving capacity of public organisations when addressing social challenges (Damanpour \& Schneider, 2009). Interest in public sector innovation has been driven by political, socio-economic, environment and technological forces, such as citizens' expectation to better utilise public resources and increase productivity, increasing demand for greater choice and quality in public services, the availability of new technologies, changing demographics of the society including aging population and immigrants, as well as the global financial and economic crisis (Bason, 2010).

By contrast with the private sector, where innovation is centered on the creation of new products and services and is rewarded financially, with increased market share and profitability, public sector innovation is mostly associated with the creation of social infrastructure and new 
forms of service delivery (Wipulanusat, Panuwatwanich, Stewart, \& Sunkpho, 2019). There is little financial reward for being innovative since public sector agencies are funded by legislative appropriations while public servants are paid with fixed salaries (Borins, 2006). Instead, innovation in the public sector is constrained both externally and internally. Externally, public sector agencies are often monopolists (Borins, 2002). The lack of competition impedes the pursuit of labour efficiency and also diminishes the incentives for innovation in the public sector (Mulgan \& Albury, 2003). In addition, the media and opposing parties are often keen to expose the public sector failures of the incumbent party including unsuccessful innovation projects, which could potentially damage the careers of the public servants involved (Borins, 2006). Internally, public organisations are usually large bureaucracies (Borins, 2002) in which rules and regulations stifle the capacity of government employees to initiate and implement creative and innovative ideas. Due to the inherent proclivity in public organisations toward legal requirements, adhering to rules and regulations is often considered paramount by leaders, rather than initiating innovation (Golembiewski \& Vigoda, 2000; Nusair, Ababneh, \& Bae, 2012). Another challenge is that public sector organisations generally have bureaucratic structures, which hinder the ability of employees to initiate and implement innovative ideas. Approval processes in the public sector can be embedded and burdensome, which restrains innovation in organisations. These challenges are forcing public organisations to implement a new style of leadership that encourages and fosters innovation, and to create organisational cultures which enhance employee creativity (McAdam, Moffett, Hazlett, \& Shevlin, 2010; Nusair et al., 2012).

Scholars have long considered the relationship between organisational attributes and an organisation's propensity to innovate (Damanpour \& Schneider, 2009; Demircioglu \& Audretsch, 2017; Fernandez \& Moldogaziev, 2013; Kim \& Chang, 2009). This perspective is important because organisational attributes provide practical implications that can be applied to improve innovation in public sectors. Kim and Chang (2009) conducted a survey to evaluate the capacity for innovation in 46 departments in the Korean central government. The results showed that leadership style, learning culture, performance-based rewards, and information and knowledge sharing appeared to raise innovation capability in governmental agencies. A study of innovation adoption in local governments in the United States by Damanpour and Schneider (2009) revealed that both leader characteristics and innovation characteristics influenced the adoption of innovation. Leaders with a pro-innovation attitude were found to positively affect innovation adoption because they tended to allocate resources and motivate employees toward the adoption of complicated innovations. Based on their study of the US Federal Government, 
Fernandez and Moldogaziev (2013) found that instilling an empowerment culture within employees improved organisational performance by creating a workplace environment which facilitated innovative behaviour, such as finding innovative ways to correct errors in service delivery and redesigning work processes. A study by Demircioglu and Audretsch (2017) focused on the likelihood of innovative activity in the Australian Public Service. The authors asserted that intrinsic factors such as experimentation and motivation to improve performance were crucial in achieving innovation in the public sector context.

These studies have critically contributed to the literature concerning the factors affecting innovation in public sectors. However, there is a lack of research into the cause-and-effect relationships between these variables and innovation outcomes. The majority of studies treat organisational attributes independently, ignoring the possible combined effects (De Vries, Bekkers, \& Tummers, 2016). In addition, most of existing empirical studies on public sector innovation were qualitative in nature, using a case-study approach (De Vries et al., 2016). Therefore, more empirical research with quantitative evidence is necessary to increase theoretical and practical understanding of how innovation outcomes can be enhanced. The aim of this paper is to address this research gap. Next, there is a description of the research model, based on a literature review of the relevant constructs and factors, and an empirical model that shows the relationships between the constructs.

\section{Research model}

\subsection{Literature review}

As discussed in recent reviews (Anderson, Potočnik, \& Zhou, 2014; Zhou \& Hoever, 2014), many influences on individual, team and organisational innovation have been studied. These works assume that innovation is itself a valuable outcome because it provides organisations with a competitive advantage (Amabile, 1988; Damanpour \& Wischnevsky, 2006). Consequently, most studies focus on the antecedents of innovation rather than its consequences (Kim, Hon, \& Crant, 2009). There are very few studies addressing the impact of innovation beyond economic performance of the firm (Glor, 2014).

This paper argues that career satisfaction is an important outcome of innovation. Career satisfaction is a more enduring attitude than job satisfaction and it includes reactions to the work itself and to anticipated benefits for one's career beyond the current job (Heslin, 2005). Career satisfaction is the sense that one is doing well in one's career $(\mathrm{Ng}$, Eby, Sorensen, \& Feldman, 
2005). Employees with higher career satisfaction are more likely to remain at organisations where they are employed (Joo \& Park, 2010) and to experience a sense of purpose and worklife balance (Heslin, 2005). This is important in both private and public sector organisations where high rates of attrition might be due to disinterest or disengagement in the job (Sullivan \& Baruch, 2009). In the current study, career satisfaction was operationalised as work meaningfulness and reward and recognition for one's work.

Workplace innovation is a combination of individual and team practices that result in new and improved ways of doing things in a workplace (Totterdill \& Exton, 2014). As well as the benefits to the organisation, such innovation can influence career satisfaction for employees (Kim et al., 2009). This study operationalised workplace innovation as individual creativity and team innovation.

The literature suggests that two main antecedents to workplace innovation are the organisation's culture and its leadership (e.g. Chan, Liu, \& Fellows, 2014; McMurray, Islam, Sarros, \& Pirola-Merlo, 2013). With regard to culture, it is proposed that an ambidextrous culture for innovation is an antecedent to both workplace innovation and career satisfaction. The concept of an ambidextrous culture for innovation is based on Ambidexterity Theory (Bledow, Frese, Anderson, Erez, \& Farr, 2009). The theory predicts that innovation will occur in organisations that successfully manage competing demands (since new systems or processes are needed to deal with the conflicting demands). In particular, an organisation may have to balance how many resources it devotes to exploring new ideas and how many resources it uses in exploiting those ideas in the production of new goods or services (Benner \& Tushman, 2003). In the current study, the ambidextrous culture for innovation was operationalised as an innovative culture and a performance-oriented culture.

Leadership is known to have strong influences on workplace innovation (Damanpour \& Schneider, 2009; Yang \& Kassekert, 2010) as well as the culture of an organisation (Gumusluoglu \& Ilsev, 2009; Kissi, Dainty, \& Liu, 2012; Yukl, 2006). Thus, for this study, leadership for innovation was operationalised by transformational leadership and consideration leadership.

Transformational leadership motivates employees, creates the organisational conditions for innovation, and leads to competitive advantages for the organisation (Chen, Lin, Lin, \& McDonough, 2012; Wipulanusat, Panuwatwanich, \& Stewart, 2017a). In particular, the 
intellectual stimulation characteristic of transformational leadership has a strong influence on innovation, because this encourages using the exploratory thinking style to approach problems from different perspectives and come up with novel solutions (Bass \& Bass, 2009). In addition, employees are not criticised for their ideas, no matter how far-fetched, nor how different they might be to the leader's own ideas (Bass \& Riggio, 2006).

Consideration leadership, first described in the Ohio State studies (Stogdill, 1950), is a leadership dimension where leaders show care and concern for their employees and express appreciation and support for them. Consideration leadership also empowers employees and thus, they are encouraged to be more innovative (De Jong \& Den Hartog, 2007).

\subsection{An empirical model for the innovation process}

The authors recently conducted a study that employed structural equation modelling (SEM) using data from a survey of 3,125 engineering professionals in the Australian Public Service (APS). Comprehensive details of the development and assessment of the model can be found in Wipulanusat, Panuwatwanich, and Stewart (2018). In brief, the extant literature supports a model in which leadership for innovation influences workplace innovation directly and also, indirectly, through ambidextrous culture for innovation. In turn, ambidextrous culture for innovation and workplace innovation both influence career satisfaction.

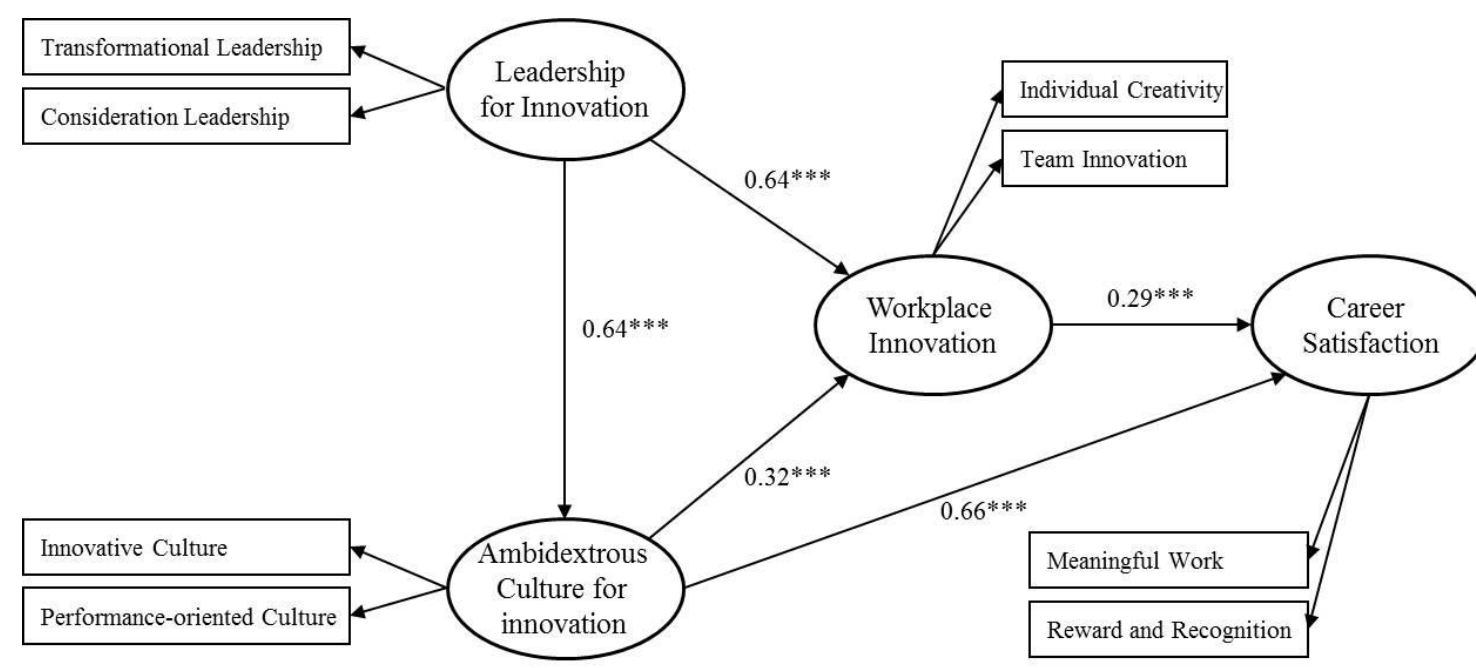

Model fit indices: $\chi^{2}=300.89, d f=15, \mathrm{GFI}=0.98, \mathrm{AGFI}=0.95, \mathrm{RMSEA}=0.08, \mathrm{RMR}=0.02, \mathrm{IFI}=0.98, \mathrm{NFI}=0.97, \mathrm{CFI}=0.98, \mathrm{TLI}=0.95$ Note: $* * * p<0.001$; For clarity, error terms and variances are not shown.

Figure 1. Research model: empirical model for innovation process (Wipulanusat et al., 2018) 
Figure 1 presents the final empirical SEM showing the causal relationships between the four constructs of the model and the factors depicting each of the constructs. Table 1 provides a description for the eight factors in the model.

Table 1. Description of research model factors

\begin{tabular}{|c|c|}
\hline Model factor & Description \\
\hline $\begin{array}{l}\text { Transformational } \\
\text { leadership }\end{array}$ & $\begin{array}{l}\text { Leader who inspires subordinates to perform, values organisational } \\
\text { objectives and goals, and motivates followers beyond expected levels of } \\
\text { work standards. }\end{array}$ \\
\hline $\begin{array}{l}\text { Consideration } \\
\text { leadership }\end{array}$ & $\begin{array}{l}\text { The degree to which a leader shows concern and expressions of support } \\
\text { for subordinates, takes care of their welfare, treats members as equals, } \\
\text { and displays warmth and approachability. }\end{array}$ \\
\hline Innovative culture & $\begin{array}{l}\text { An organisation which orients toward experimenting with new solutions } \\
\text { by exploring new resources, breaking through existing norms, and valuing } \\
\text { flexibility, adaptability, creativity, risk taking, and entrepreneurship. }\end{array}$ \\
\hline $\begin{array}{l}\text { Performance-oriented } \\
\text { culture }\end{array}$ & $\begin{array}{l}\text { An organisation having performance-oriented culture is categorised into } \\
\text { three elements: (a) strongly developed goal orientation; (b) a focus on } \\
\text { task performance; and (c) a strong emphasis on quality of service } \\
\text { delivery. }\end{array}$ \\
\hline Individual creativity & $\begin{array}{l}\text { The individual ability to develop practical and new solutions to workplace } \\
\text { challenges, and provide a tangible and useful outcome for an } \\
\text { organisation. }\end{array}$ \\
\hline Team innovation & $\begin{array}{l}\text { The introduction or application within a team of ideas, processes, } \\
\text { products, or procedures that are novel to the team and are designed to be } \\
\text { useful. }\end{array}$ \\
\hline Meaningful work & $\begin{array}{l}\text { The amount of significance and positive meaning that employees perceive } \\
\text { in their work, and an individual's subjective experience of existential } \\
\text { significance or purpose of work. }\end{array}$ \\
\hline $\begin{array}{l}\text { Reward and } \\
\text { recognition }\end{array}$ & $\begin{array}{l}\text { A sense of return on employees' performances that come in terms of } \\
\text { financial rewards, pay and benefits, and promotions, as well as in terms of } \\
\text { respect from co-workers, challenging work, and public recognition. }\end{array}$ \\
\hline
\end{tabular}

Leadership for innovation is considered an exogenous construct that has a strong and positive impact on ambidextrous culture for innovation $(0.64, p<0.001)$ and workplace innovation $(0.64, p<0.001)$. Ambidextrous culture for innovation shows a moderate and positive effect on workplace innovation $(0.32, p<0.001)$. The path coefficient from workplace innovation to career satisfaction has a moderate and positive influence $(0.29, p<0.001)$. Lastly, there is a significant relationship from ambidextrous culture for innovation to career satisfaction, represented by the strong and positive standardized coefficient $(0.66, p<0.001)$.

Overall, the model provides meaningful connections among the climate for innovation constructs (i.e. leadership for innovation and ambidextrous culture for innovation) that can be 
implemented strategically to increase workplace innovation and, in turn, strengthen career satisfaction. The model could be implemented to help resolve the current shortage of engineering professionals in government departments. The findings highlight the importance of providing engineers with sufficient opportunities to engage in creative and innovative projects to develop their professional careers.

However, a limitation of the model was that the factors were considered as indicators representing latent constructs, which only provided an abstract causal explanation (Anderson $\&$ Vastag, 2004). Therefore, only the relationships among the broad organisational perspectives (model constructs) were depicted in this model, thereby providing only an overarching understanding of the priority of the specific activities (model factors). That is, the model cannot indicate which strategies require the highest priority for change and development in order to accomplish organisational outcomes (Panuwatwanich, Stewart, \& Mohamed, 2009). To address this limitation, a Bayesian network $(\mathrm{BN})$ analysis was conducted to enhance the explanatory power of the SEM in order to examine the causality within the empirical model. The BN can be employed as a decision-making tool to facilitate innovation in the APS. Therefore, BN increased the model's explanatory capability by analysing the variables at the factor level to reveal the pathways to desired outcomes, and explain the priority and relationships among the factors.

\section{Bayesian network}

Using probability theory, the BN generates a causal map which is applied for knowledge representation and reasoning under uncertainty. $\mathrm{BN}$ is implemented to conduct statistical inference from evidence acquired from observed events, when there is also a requirement to forecast additional events yet to be observed. BN is implemented to conduct statistical inference from evidence acquired from observed events, when there is also a requirement to forecast additional events yet to be observed. In this study, BN was applied to provide a visual assessment for a decision-support framework for problems involving uncertainty, complexity, and probabilistic reasoning which was used to evaluate various scenarios and/or the impact of possible decisions. The mathematical model applied in BN relies on Bayes' theorem of probability theory which can be conveyed as hypotheses and evidence (Niedermayer, 2008). Bayes' theorem, which describes how prior knowledge about hypothesis $H$ is updated by observed evidence $E$, is shown in Eq. 1. 


$$
P(H / E)=\frac{P(E / H) \cdot P(H)}{P(E)}
$$

By using $\mathrm{BN}$, the belief in hypothesis $H$ can be updated given the additional evidence $E$. Where $P(H / E)$ is called the posterior probability, which is the probability that hypothesis $H$ is in a particular state, after considering the effect of the evidence provided; $P(E / H)$ is called the conditional probability, which is the likelihood of the evidence, given the hypothesis to be tested; $P(H)$ is called the prior probability of the hypothesis, which is the likelihood that hypothesis $H$ will be in a particular state, prior to consideration of any evidence; $P(E)$ is independent of hypothesis $H$ and can be regarded as a normalising or scaling factor (Kragt, 2009). Bayes' theorem is useful in practice to estimate unknown $P(H / E)$ from three probability terms $P(E / H), P(H)$, and $P(E)$.

BN is an effective modelling tool because it allows both inferences and sensitivity analysis, as well as visualisation and quantification of the propagation of effects between variables (de Oliveira, Possamai, Dalla Valentina, \& Flesch, 2012). BN is a methodology comprising of quantitative and qualitative elements (Sharma \& Chanda, 2017). The qualitative approach involves structural learning, which produces graphical representation of the independence among variables and illustrates statistical dependencies through directed acyclic graphs (DAG). This approach conceptualises the topology of the $\mathrm{BN}$ using connected nodes which depict important domain variables, and arrows that represent the causal relation. The quantitative approach provides parameter learning and domain knowledge using the degree of dependency represented in probabilistic terms. This is achieved by coding the conditional independencies between variables and integrating their joint distribution. A set of conditional probability tables (CPT) designate the probability distribution. Each node, treated as random variables, has a CPT that stipulates the quantitative probability information. When a variable has no parent node, it is represented by a marginal probability distribution. The outcome is illustrated by the probability value of each child node in the CPT, where every possible combination of values of its parent nodes is considered to be the cause of an event (de Oliveira et al., 2012). The results can then be used to conduct a sensitivity analysis where the differences among these conditional and marginal probabilities are examined to determine which nodes have the maximum impact on target variables (Cardenas, Voordijk, \& Dewulf, 2017).

BN also provides an inference engine to make reasonable interpretations of the model parameters. It has two applications: prediction and diagnosis (Sharma \& Chanda, 2017). It is 
an effective method to predict the efficiency of different strategies and to evaluate the impact of various scenarios and potential strategic actions (Mohammadfam, Ghasemi, Kalatpour, \& Moghimbeigi, 2017). In terms of diagnosis, the reasoning is determined by identifying causes from a set of observations to establish the most likely strategies from target variables (Ülengin, Önsel, Aktas, Kabak, \& Özaydın, 2014). Therefore, BN can be applied to support managerial decisions when determining the interactions between various strategies and target variables.

\section{Research method}

\subsection{Linking SEM to BN}

This study applied an integrated approach by linking SEM to BN. While both approaches are very useful for quantitative analysis, both methods have certain limitations that need to be considered. Because latent constructs are the causes of their indicators (observed variables), SEM can only predict statistical results at the hypothetical level of latent constructs (Anderson, Mackoy, Thompson, \& Harrell, 2004). Moreover, SEM is not appropriate to effectively reveal the causal relationships between all latent constructs and indicators and thus, can only explain established theoretical relationships of constructs (Ekici \& Ekici, 2016; Gupta \& Kim, 2008). Observable consequences from potential managerial action cannot be predicted using SEM, therefore it has no causality inference capability (Anderson \& Vastag, 2004; Hahn, Lee, \& Jo, 2015). It is limited in its support of scenario analysis for managerial decisions. Thus, the primary weakness of SEM is its inability to convert knowledge from the theoretical model into managerial actions (Anderson \& Vastag, 2004). For BN, it also has some limitations that restrict its performance for theoretical construction because DAG development relies on expert judgement, which is only as accurate as the reliability of the expert's background knowledge (Boehmke, Johnson, White, Weir, \& Gallagher, 2016). BN can only provide theoretical explanations which are not as reliable as an empirical validation by SEM (Anderson et al., 2004). BN develops relationships based on conditional independence, and thus, cannot discern between causal and spurious relationships since determining the causal relationships is not possible when using only statistical data (Pearl, 1998). These limitations of SEM and BN can be addressed by applying a theoretically based and empirically validated model from SEM to develop $\mathrm{BN}$ at the factor level. By applying the integrated approach, this study identifies causal relationships among factors that affect workplace innovation and career satisfaction, and then 
conducts scenario analysis to further identify specific managerial actions that can be implemented to improve career satisfaction.

For this study, SEM provided an empirically validated model based on theoretical construction appropriate to develop a causal map. The BN was performed to assess and refine causal relationships between the factors identified in the empirical model. The BN was developed through the aggregation of SEM to attain qualitative causal relationships and by analysing the data to learn the quantitative probabilities. The first step involved creating a Bayesian causal map, i.e. directed acyclic graph (DAG). The graph is acyclic when paths which begin and end in one node are prohibited if the arcs flow in the same direction. DAG has a set of nodes and directed arcs, where the nodes depict the factors, and the causal relations between them are presented by the directed arcs. The arcs between the nodes indicate a dependency relationship and direction of influence, while the CPT establishes the strengths of these relationships. The DAG also allows the analysis of conditional independencies, where an absence of an arc between one node and its successors illustrates conditional independence. Conditional independence, which implies there is no direct causal relationship, is significant to make inferences because it establishes the relevance of the data on one node in relation to another (Anderson \& Vastag, 2004; de Oliveira et al., 2012).

\subsection{Causal modelling}

The DAG was constructed based on an empirically validated model that was developed using SEM. The process of developing the DAG followed the approaches used in studies by Gupta and Kim (2008) and Panuwatwanich et al. (2009). The DAG development began by analysing the chronological sequence of the constructs. The framework followed the empirical model shown in Figure 1. The framework illustrates the sequence of constructs where leadership for innovation directly affects the culture for innovation and workplace innovation. Culture for innovation directly impacts workplace innovation and career satisfaction. Therefore, the output from climate for innovation consists of workplace innovation and career satisfaction.

In the DAG, all causal relationships of factors within each construct are incorporated in the causal map. The reasoning of which causal factors precede the effect factors, can be used to establish the between-constructs relationships (Cardenas et al., 2017). The between-construct structures confirmed the strong and statistically significant relationships. For example, leadership for innovation has a positive influence on ambidextrous culture for innovation (0.64, 
$p<0.001)$ and workplace innovation $(0.64, p<0.001)$. The factors within the associated constructs were firstly separated and then connected to the factors determined by the betweenconstruct relationships (Anderson \& Vastag, 2004). Because the two factors extracted to characterise leadership for innovation included transformational leadership and consideration leadership, there was no causal relationship between these two factors within this construct. Transformational leadership and consideration leadership were found to be direct causes of innovative culture and performance-oriented culture. Furthermore, transformational leadership and consideration leadership were considered to be direct causes for individual creativity and team innovation. This association between A and B is based on a common cause $\mathrm{C}$, which can be denoted as $\mathrm{A} \leftarrow \mathrm{C} \rightarrow \mathrm{B}$. The causal mechanisms were identified as follows:

- Innovative culture $\leftarrow$ Transformational leadership $\rightarrow$ Performance-oriented culture

- Innovative culture $\leftarrow$ Consideration leadership $\rightarrow$ Performance-oriented culture

- Individual creativity $\leftarrow$ Transformational leadership $\rightarrow$ Team innovation

- Individual creativity $\leftarrow$ Consideration leadership $\rightarrow$ Team innovation

After all the causal relationships among factors were identified, the DAG was constructed based on the empirically validated model, as shown in Figure 2. The DAG illustrates a link between transformational leadership and innovative culture which means that innovative culture is a child of transformational leadership. In other words, transformational leadership is a parent of innovative culture.
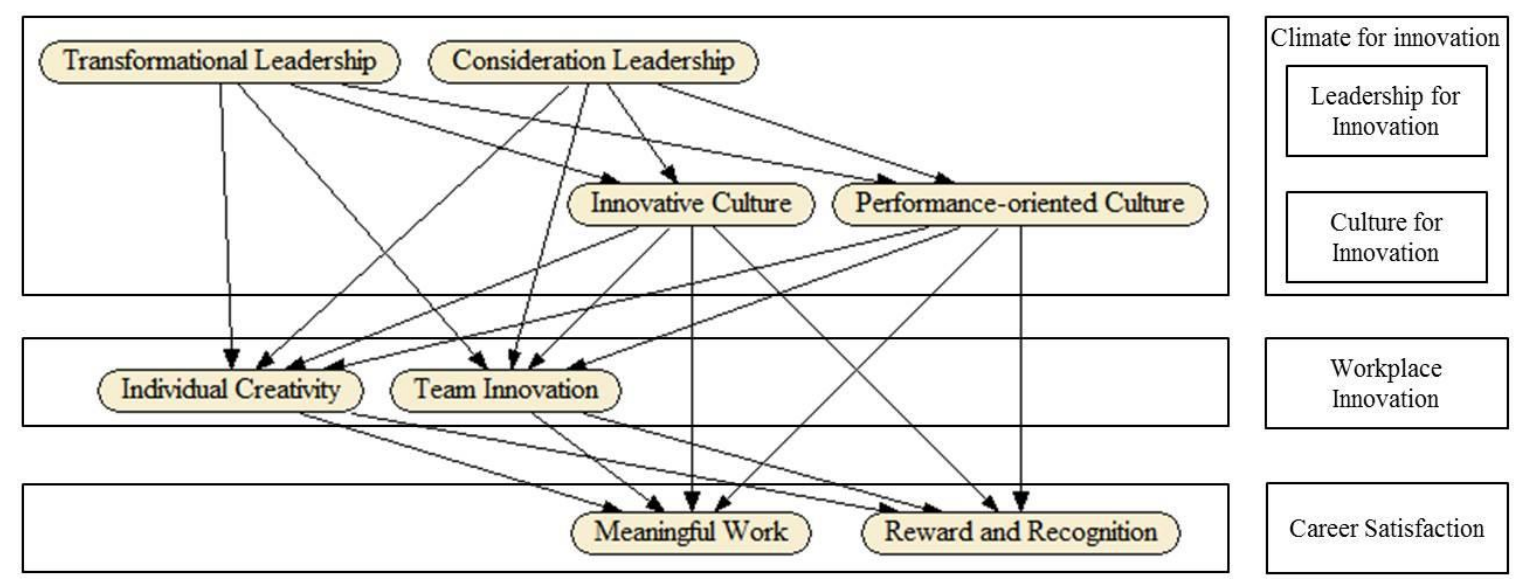

Figure 2. The directed acyclic graph representing the dependencies among the factors

While the DAG can determine the qualitative relationships among factors, a further step is required to quantify the conditional probability table (CPT). This step involves the quantitative part of the BN which calculates the conditional probabilities of nodes. This is useful 
because it determines the exact relationships among factors. This means the probability of various states of a node is conditional on the different configurations of its parent states (Mohammadfam et al., 2017). BN also depends on the chain rule which is the joint probability distribution of each variable, whereby the BN can calculate the marginal and conditional probabilities for each node in the network (Chanda \& Goyal, 2019; Yang \& Xu, 2017).

If the DAG has $N$ variables, $X_{1}, X_{2}, \ldots, X_{n}$ is presented as nodes. The set of parents' nodes with a direct link to $X_{i}$ can be represented by $\pi_{i}$. The conditional probability distribution can be denoted by $P\left(X_{i} \mid \pi_{i}\right)$. The joint probability of the network can be illustrated in Eq. 2 .

$$
P\left(X_{1}, X_{2}, \ldots, X_{n}\right)=\prod_{i=1}^{N} P\left(X_{i} \mid \pi_{i}\right)
$$

The joint probability distribution, called the chain rule of probability theory, defines a factorisation of several conditional probability distributions. The joint probability distribution also involves the specification of a CPT for each node (Fuster-Parra, García-Mas, Ponseti, Palou, \& Cruz, 2014). The independencies from the DAG were interpreted to the probabilistic model which was used to determine the factors affecting the innovation process in the APS.

\subsection{Bayesian network construction}

Once the DAG has been developed, the BN states need to be defined for the purpose of building a model. Generally, variables may be either discrete or continuous and these are dependent upon the measured phenomena. A discrete variable is represented by a finite set of fixed values. Alternatively, a continuous variable consists of any value from a selected range (Chen \& Pollino, 2012). In this study, a 5-point scale was used to assign values to factors. A continuous variable can be converted to a discrete variable to determine the $\mathrm{BN}$ states. To do this, continuous values must be discretised in terms of the states of each node. This method was used to support the managerial capability of the $\mathrm{BN}$ and to avoid mathematical complexity (Gupta \& Kim, 2008). In this study, the equal-width method, which discretises the variables by dividing the range of values into a predefined number of intervals of equal-width, is inappropriate due to an uneven distribution of the data (Chen \& Pollino, 2012; Yang \& Xu, 2017). This study determined the states of the $\mathrm{BN}$ nodes using the same assumptions as those adopted in de Oliveira et al. (2012). Given the chance of occurrence of each BN state, the numerical values of factors, based on a 5-point scale, were discretised by classifying the scale into three states: 
low, medium, and high. Specifically, survey score ranging between 1-2.5, 2.5-4 and 4-5 were classified as Low, Medium and High BN states, respectively.

In this study, the parameter learning of the BN was developed using Netica software. Netica automatically determines the parameter learning process, creates the cognitive map, analyses the probabilistic values for each parameter, and subsequently enables both inferences and sensitivity analysis. The parameter learning process automatically learns from a file of cases. The spreadsheet was constructed, for each of the 3,125 survey respondents, with columns corresponding to the variables of interest for each node, and each row represented the corresponding BN state in each node. The DAG was developed in the software by drawing the nodes in the network and linking them to indicate their causal relationships. After constructing the DAG, all the cases in the spreadsheet were incorporated in Netica through a compilation process. There are three automated algorithms available in Netica, which can be used for parameter learning of the CPTs: counting, expectation-maximisation (EM) and gradient descent. The most straight forward method to calculate the CPT is the counting algorithm (Ticehurst, Curtis, \& Merritt, 2011). In addition, the counting algorithm has been accepted as a true Bayesian learning algorithm, and should be implemented whenever possible (Norsys Software Corp., 2010). The spreadsheet also met the requirement of the counting algorithm since there were no missing data in the file of cases. Therefore, the counting algorithm was used to quantify the CPT underlying all nodes to develop the BN model.

The occurrence probability of each situation was calculated to determine the probability distribution values. The probability of each state for a specific child node is determined by the CPT for all combinations of the parents' states. Table 2 shows the CPT that presents the probability distribution of the innovative culture node. For example, when the transformational leadership and consideration leadership nodes are both in the low state, the probabilities of low, medium and high states of the innovative culture node are 72.4, 25.0 and 2.6 percent, respectively. These probabilities show the beliefs for the three states, which total 100 percent.

The CPT is also used to check the minimum sample size required for the parameter estimation. The node with the greatest number of cells in its CPT decides the least number of required cases (Mohammadfam et al., 2017). For example, in this study, the individual creativity node can be used in this regard. Accordingly, this node with three states has four incoming arcs. The 3,125 samples available in this study well exceeded the acceptable sample size for reliable CPTs (i.e. $3 \times 3^{4}=243$ ). 
Table 2. Conditional probability table for innovative culture node

\begin{tabular}{llccc}
\hline \multirow{2}{*}{$\begin{array}{l}\text { Transformational } \\
\text { Leadership }\end{array}$} & $\begin{array}{l}\text { Consideration } \\
\text { Leadership }\end{array}$ & \multicolumn{3}{c}{ Innovative Culture } \\
\cline { 3 - 5 } & Low & 72.4 & 25.0 & 2.6 \\
Low & Medium & 50.4 & 44.4 & 5.2 \\
Low & High & 40.9 & 51.6 & 7.5 \\
Low & Low & 26.7 & 66.7 & 6.6 \\
Medium & Medium & 27.1 & 62.8 & 10.1 \\
Medium & High & 19.4 & 62.9 & 17.7 \\
Medium & Low & 20.0 & 40.0 & 40.0 \\
High & Medium & 12.5 & 58.8 & 28.7 \\
High & High & 9.2 & 49.5 & 41.3 \\
High & & &
\end{tabular}

Once the CPTs have been learned, the 'Compile the net' feature was used to determine the probabilistic inference. This learning process calculated the probabilities of all nodes in the $\mathrm{BN}$, which were presented graphically in the form of a belief bar. The current innovation management context of the APS was represented by the BN in Figure 3. The compiled network has a total of 8 nodes and 20 causal relationships between nodes in the BN.

Each node has different probabilities which are presented as percentages in the three states: high, medium and low (see Figure 3). The belief on the innovative culture node, for instance, shows that the high state is equal to 25.3 percent, which can be expressed as $P($ innovative culture $=$ high $)=0.253$. While 55.5 percent of respondents believed that there was a medium state of innovative culture in their organisation, 19.2 percent considered it to be at a low state. Therefore, because the medium state has the highest percentage, a medium innovative culture is likely to occur. The two values expressed at the bottom of each numerical node are the mean and standard deviation for that node. For example, the mean value of innovative culture is equal to 3.18. This makes it apparent that there is considerable room for improvement by inculcating an innovative culture in the APS.

After constructing the $\mathrm{BN}$, it was observed that some nodes were characterised as dependent variables of other nodes. For instance, transformational leadership and consideration leadership directly influence innovative culture. As shown in Figure 3, a high state of transformational leadership (47.8 percent) and a high state of consideration leadership (73.9 percent) are likely to take place. These two nodes can result in the innovative culture node, which has a probability of 55.5 percent of being in a medium state. These two nodes also act separately in determining a high probability of performance-oriented culture. Thus, 
transformational and consideration leadership generates a medium probability of innovative culture; but, at the same time, promotes a high chance of performance-oriented culture. Also, individual creativity is dependent on transformational and consideration leadership as well as innovative and performance-oriented culture. Additionally, transformational and consideration leadership have a direct effect on individual creativity as well as an indirect effect through their influence on innovative and performance-oriented culture. Our sample shows a high level of probability for individual creativity. This phenomenon occurs in the same manner for team innovation.

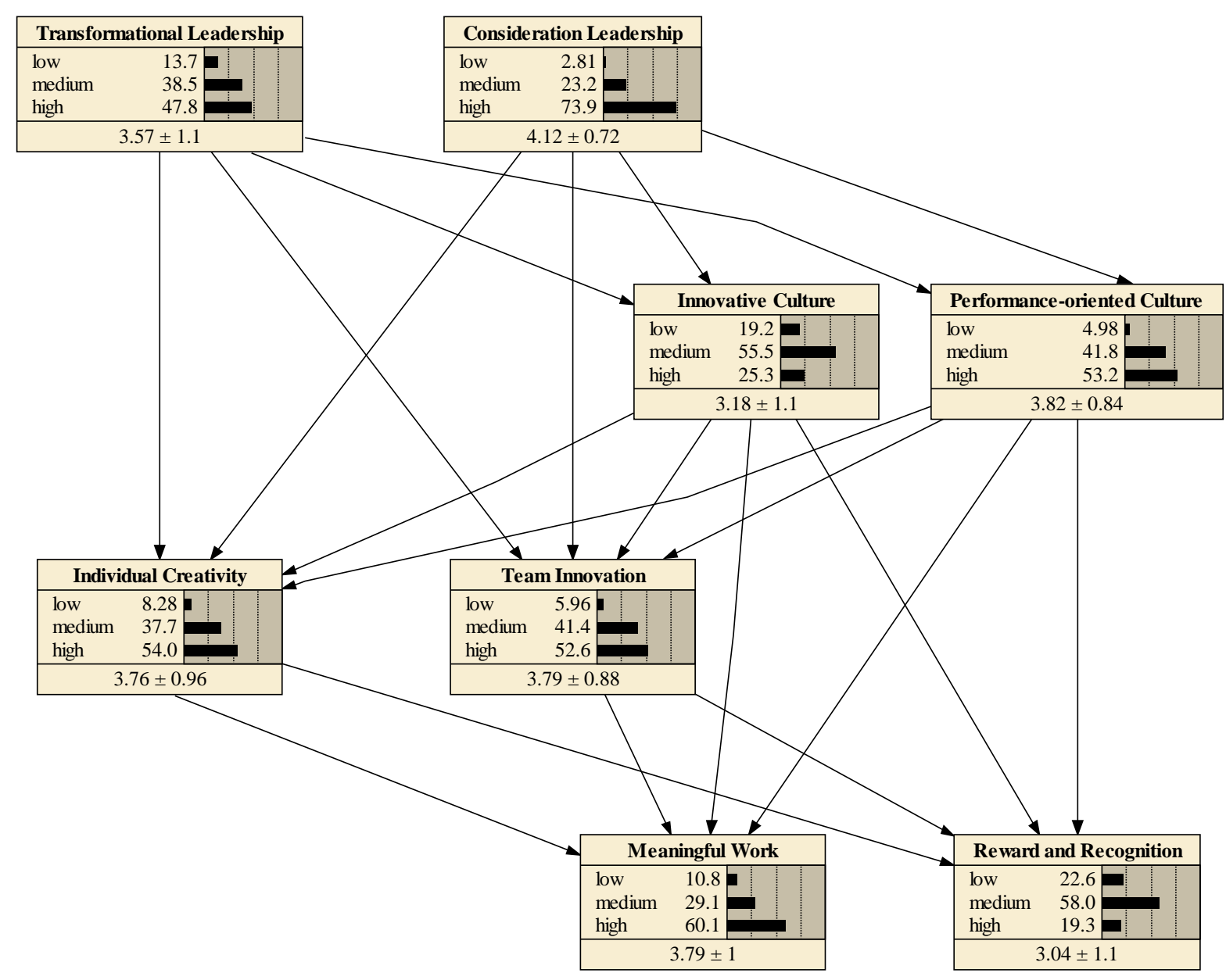

Figure 3. The Bayesian network for innovation management

Career satisfaction, meaningful work and reward and recognition factors are dependent upon individual creativity, team innovation and innovative and performance-oriented culture. Leaders also indirectly promote meaningful work, as well as reward and recognition, through their influence on culture factors (i.e. innovative and performance-oriented culture) and workplace innovation (i.e. individual creativity and team innovation). These causal 
relationships lead to a high state for meaningful work (60.1 percent). Interestingly, engineers in the APS have reported a medium level of probability for the reward and recognition node (58.0 percent), which correlates with the mean value of 3.04. Therefore, it is necessary to implement a strategy to promote reward and recognition in an effort to increase career satisfaction and address current shortages in engineering professionals in the APS.

\section{Results and Discussion}

\subsection{Sensitivity analysis}

Sensitivity analysis is the diagnostic inference process of how the uncertainty of the output variable can be allocated to the various sources of uncertainty of the input variables (Cardenas et al., 2017; Yang \& Xu, 2017). Sensitivity analysis can identify which input variables lead to the greatest reduction of uncertainty in the prediction of the output variable (Laskey, 1995). Therefore, sensitivity analysis is a tool for decision makers to determine critical input variables and how variations in these input variables impact the output variable (Laskey, 1995; Sturlaugson \& Sheppard, 2015).

Suppose $Q$ is an output variable and $F$ is an input variable. The degree of sensitivity of $Q$ to $F$ can be denoted by the variance reduction $V_{r}$ (Eq. 3), which is the expected reduction in the variance of the output variable resulting from the value of an input variable (Ekici \& Ekici, 2016)

$$
V_{r}=V(Q)-V(Q \mid F)
$$

$V(Q)$ is the variance of the output node $Q$, and $V(Q \mid F)$ is the variance of the output node given the input node $F$.

The input variable with the greatest variance reduction is most likely the variable that changes the beliefs of the output variable by the greatest amount, thereby providing it with the most explanatory power over the output variable (Ülengin et al., 2014). A high variance reduction for the input variable implies that the output variable has a high sensitivity to changes in this input variable (Marcot, 2012).

Netica provides a capability for the sensitivity analysis to determine the extent that the belief and mean value of the output node can be influenced by other input nodes in order to 
identify which nodes are the significant factors in crystallising the states of the output node (Ülengin et al., 2014). To conduct the sensitivity analysis, the 'sensitivity to findings' feature of Netica was performed to identify which input nodes had the greatest explanatory power on the target node.

The sensitivity analysis presents the variance reduction and the percentage of variance reduction for each of the input nodes. Moreover, in order to provide a clearer comparison of the relative sensitivity, a normalised variance reduction was calculated by dividing the percent variance reduction of each node by the highest percent variance reduction (Brandmayr, Kerber, Winker, \& Schramm, 2015). Variance of beliefs indicates the uncertainty of these estimations (Cinicioglu, Önsel, \& Ülengin, 2012).

Table 3. Sensitivity analysis of individual creativity node

\begin{tabular}{lllll}
\hline Factor & $\begin{array}{l}\text { Variance } \\
\text { reduction }\end{array}$ & Percent & $\begin{array}{l}\text { Normalised } \\
\text { variance reduction }\end{array}$ & $\begin{array}{l}\text { Variance of } \\
\text { beliefs }\end{array}$ \\
\hline Transformational leadership & 0.1128 & 12.30 & 1.00 & 0.0221 \\
Innovative culture & 0.1069 & 11.70 & 0.95 & 0.0192 \\
Meaningful work & 0.1051 & 11.50 & 0.93 & 0.0147 \\
Reward and recognition & 0.0825 & 9.00 & 0.73 & 0.0115 \\
Consideration leadership & 0.0511 & 5.59 & 0.45 & 0.0063 \\
Team innovation & 0.0291 & 3.18 & 0.26 & 0.0039 \\
Performance-oriented culture & 0.0201 & 2.19 & 0.18 & 0.0017 \\
\hline
\end{tabular}

Sensitivity analysis was conducted to identify which critical factors within the climate for innovation had the greatest influence on workplace innovation and career satisfaction (refer to Figure 2). For workplace innovation, the individual creativity node has a lower mean value than team innovation which suggests there is considerable opportunity to increase individual creativity. Thus, the individual creativity node was selected as the target node to determine its critical factors, and the results of the sensitivity analysis have been summarised in Table 3 . When the variance reduction of the input variable is relatively high, this suggests that the output variable's uncertainty is highly sensitive to the input variable. If the measure is relatively low, the output will be fairly insensitive to the associated factor (Cardenas et al., 2017).

Sensitivity analysis provided the ranking of the factors according to their explanatory power on individual creativity. The critical factors are transformational leadership and innovative culture with variance reductions of 12.3 and 11.7 percent, respectively. It can be 
inferred that transformational leadership and innovative culture have the greatest explanatory power over individual creativity.

As the ultimate goal of the $\mathrm{BN}$ is to improve reward and recognition, this node was selected as a target node for the sensitivity analysis. In Table 4, factors were ordered according to their variance reduction. Innovative culture had the maximum variance reduction of 19.5 percent, while the variance reduction of the other nodes was comparatively small. Innovative culture is a dominant factor in its influence on the reward and recognition node. Therefore, fostering innovative culture is necessary for the fulfilment of reward and recognition.

Table 4. Sensitivity analysis of reward and recognition node

\begin{tabular}{lllll}
\hline Factor & $\begin{array}{l}\text { Variance } \\
\text { reduction }\end{array}$ & Percent & $\begin{array}{l}\text { Normalised } \\
\text { variance reduction }\end{array}$ & $\begin{array}{l}\text { Variance } \\
\text { of beliefs }\end{array}$ \\
\hline Innovative culture & 0.2266 & 19.50 & 1.00 & 0.0260 \\
Individual creativity & 0.1023 & 8.79 & 0.45 & 0.0091 \\
Transformational leadership & 0.0552 & 4.75 & 0.24 & 0.0036 \\
Meaningful work & 0.0474 & 4.07 & 0.21 & 0.0031 \\
Team innovation & 0.0392 & 3.37 & 0.17 & 0.0034 \\
Performance-oriented culture & 0.0274 & 2.36 & 0.12 & 0.0025 \\
Consideration leadership & 0.0101 & 0.87 & 0.04 & 0.0007 \\
\hline
\end{tabular}

\subsection{Scenario analysis}

Scenario analysis has become a simple and practical method to assess and manage risk and uncertainty in business, government and academia (McBurney \& Parsons, 2003). It is a tool for strategic policy analysis that allows policy makers to consider their decisions and assess potential consequences (Boehmke et al., 2016). Scenarios are defined as hypothetical sequences of future situations derived from original events to gain insights on causal relations and decision environments (Kayakutlu, Daim, Kunt, Altay, \& Suharto, 2017). Scenarios can be regarded as plausible and evidence-based narratives that policy makers can use to identify multiple situations leading to different scenarios (Rudd, Hajkowicz, Boughen, Nepal, \& Reeson, 2015). Scenario analysis is conducted by inserting potential evidence representing a particular scenario which allows the simulation of potential outcomes in terms of probability distribution.

Scenario analysis has been accepted as an effective tool for strategic management in both the private and public sector. In the private sector, Royal Dutch Shell is credited for the development of scenario analysis which has been used to support the executive board for strategic decision-making purposes since the 1960s (Wilkinson \& Kupers, 2013). This tool 
assisted the company to effectively overcome the oil crises of the late 1970s and early 1980s (Hahn et al., 2015). For the public sector, scenario analysis was adopted by the Queensland Government to determine how digital technology could impact on public service delivery. These scenarios have been used for strategic planning to provide a mechanism to test the viability of alternative strategy options and formulate appropriate contingency plans to improve the digital marketplace for public services (Rudd et al., 2015). Both the public and private sectors have applied scenario analysis as an effective and efficient tool for strategic foresight.

This study applied BN for scenario-based simulations to provide a decision support framework to manage the innovation process. The $\mathrm{BN}$ can be used for both forward and backward inferences to allow predictions and diagnostics based on any set of selected factors. The abilities of $\mathrm{BN}$ to infer posterior probabilities and to conduct multi-directional reasoning were adopted to simulate various scenarios under uncertainty. When an intervention instantiates the values of another variable or set of variables, the conditional probabilities of other variables are updated. Instantiation of a variable or a set of variables, called the evidence, can be used for the simulation of various scenarios. The conditional probabilities of all nodes in given scenarios can provide plausible outcomes of the organisational change. The consequence of an intervention can be measured by the relative magnitude of the percent change from preintervention mean values to post-intervention mean values. The scenario analysis was applied to manage changes for scenarios using "what-if" and "goal seeking" analysis.

"What if" analysis, which refers to deductive reasoning or forward inference, is a prediction based on pre-set input variables from causes to effects. Decision makers can apply forward inference to measure the influence of changing factor(s) on the attainment of specific goals. Three alternative scenarios were simulated in this study to assess "what if" analysis to gain insight into probable consequences. "Goal seeking" analysis adopts backwards inference which is the application of Bayes' theorem. This is a diagnostic approach drawing a cause from a conclusion by calculating the occurrence likelihood of input variables causing pre-specified output variables (Bertone et al., 2018; Hahn et al., 2015). The main purpose is to determine how to manipulate the factors and their states to achieve the chances of 100 percent occurrence of a high state of the target node.

\subsubsection{Scenario 1: The effect of transformational leadership}

As previously shown in Table 3, when the individual creativity node was selected as a target node to investigate its key factors, the sensitivity analysis results illustrated that the maximum 
variance reduction was caused by the transformational leadership node. The impact of transformational leadership on other nodes was evident when the chance of 100 percent occurrence of a high state was assumed. As shown in Figure 4, this led to the chance of high innovative culture increasing to 38.4 percent. The mean value of innovative culture in this situation reached 3.52 , hence representing an increase of 10.7 percent $(3.18 \rightarrow 3.52)$. In addition, the chance of high individual creativity increased from 54.0 to 71.2 percent. This reflected an increase in the mean value of individual creativity by 7.7 percent $(3.76 \rightarrow 4.05)$. Therefore, transformational leadership is essential to improve both innovative culture and individual creativity.

Leaders with transformational leadership style show support and consideration for staff. These behaviours increase employee creativity and innovation in the workplace (GarcíaMorales, Jiménez-Barrionuevo, \& Gutiérrez-Gutiérrez, 2012; Yang \& Kassekert, 2010). Transformational leadership has four characteristics (Bass \& Riggio, 2006): individualised consideration, intellectual stimulation, inspirational motivation, and idealised influence.

The transformational leader gives individualised consideration to each follower's needs for growth and achievement by acting as a coach or mentor. Transformational leaders assist subordinates to become fully actualised and to develop work-related competencies with consideration and empathy through personal attention. Such leaders have the capacity to build and develop subordinates' sense of determination and self-confidence (Bass \& Riggio, 2006). New learning opportunities are created within a supportive climate according to employee differences in terms of desires and needs. Transformational leadership can result in reciprocation from employees through increased creativity and innovation in response to the individualised consideration they receive (Chen et al., 2012). Creativity and innovation are also achieved when leaders allow employees autonomy and discretion to reframe new problems, and question assumptions and the status quo with novel approaches (Gumusluoglu \& Ilsev, 2009; Wipulanusat, Panuwatwanich, \& Stewart, 2017c). 


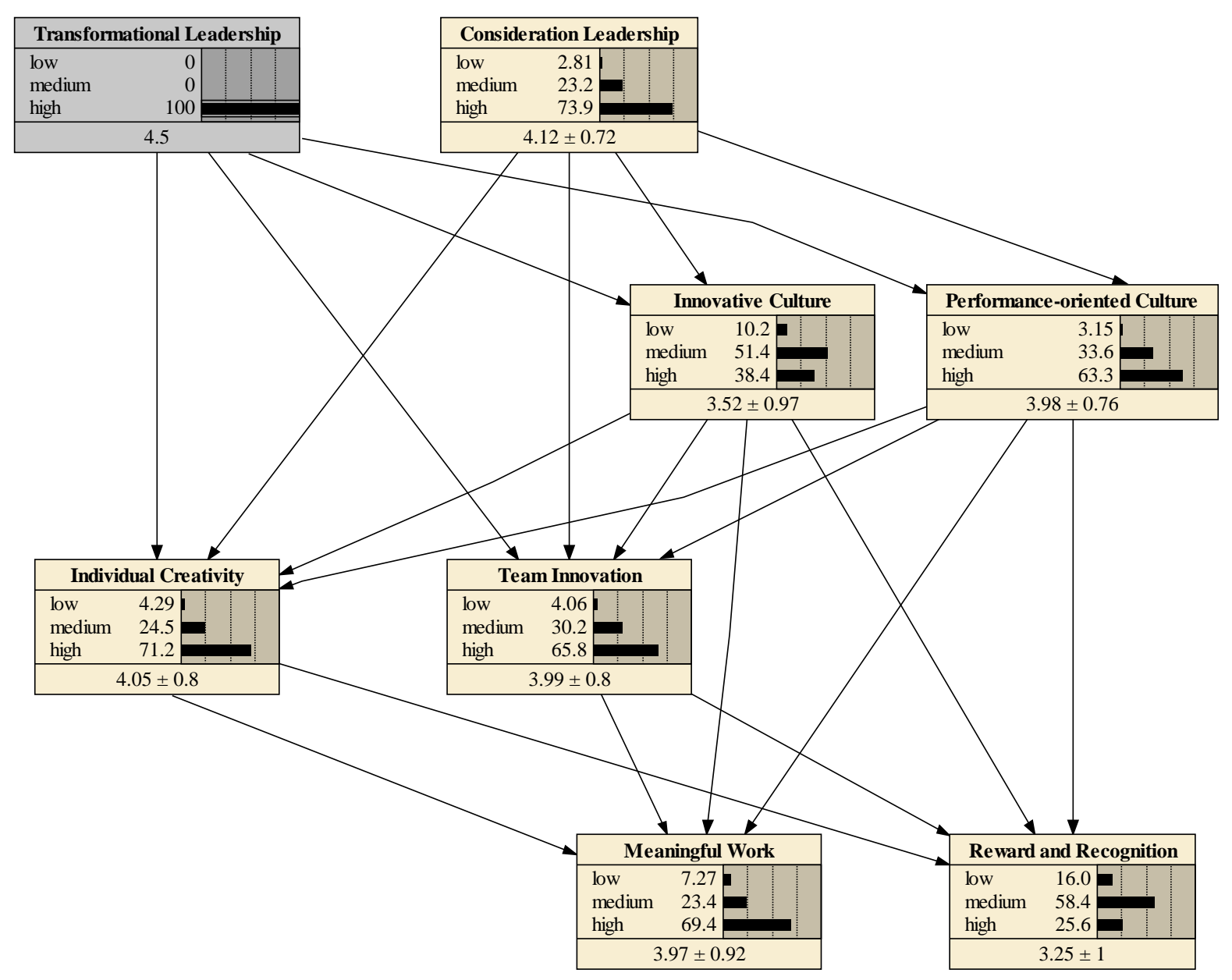

Figure 4. The effect of transformational leadership

By practicing intellectual stimulation, transformational leaders encourage subordinates to adopt an exploratory thinking style to find new ideas for problems and create solutions from different perspectives. Creativity is also stimulated when employees' ideas are not publicly criticised and they are not concerned if their approaches differ from the leaders' ideas (Bass \& Riggio, 2006). Transformational leaders utilise and encourage logic and intuition in coping with problems. Intellectual stimulation, together with individualised consideration, are the basic characteristics of a competent organisational coach and mentor.

In providing inspirational motivation, transformational leaders behave in ways that encourage followers to focus on organisational objectives and motivate their subordinates by providing meaning and challenge to their jobs (Bass \& Riggio, 2006). These leaders build relationships with their followers through interactive communication, and encourage individual and team spirit, and collaboration. They also communicate an exciting vision of the future, 
increased employee cooperation, and direct subordinates to approaches that achieve goals (Nusair et al., 2012; Oberfield, 2012).

Transformational leaders are altruistic role models whose idealised influences induce the admiration, respect, and trust of subordinates. They also display charismatic behaviour by expressing confidence in the organisational vision; showing a sense of purpose, determination, persistence, and trust in other people; and emphasising accomplishments (Bass \& Riggio, 2006). The transformational leader's idealised influence plays a vital function in stimulating creativity and innovation by boosting the significance of these behaviours through the leader's own words and actions (Dwivedi, Shareef, Pandey, \& Kumar, 2013). In public sectors, the negative ramifications of risk-taking in innovative projects can be drastic and can include political damage to the government, public criticism, possible legal consequences, diminished career prospects, and damage to personal reputation. Transformational leaders support innovation by establishing an innovative culture in which employees are not concerned about negative ramifications, when they implement new ideas into practice (Amabile, Schatzel, Moneta, \& Kramer, 2004; García-Morales et al., 2012).

\subsubsection{Scenario 2: The effect of innovative culture}

Sensitivity analysis reveals that the highest explanatory factor of the reward and recognition node was innovative culture. To assess the significance of innovative culture, evidence of a high state was entered for this node, as shown in Figure 5. The results indicated that the odds of high individual creativity increased to 76.2 percent and the mean value increased by 9.3 percent $(3.76 \rightarrow 4.11)$. The chance of high reward and recognition would reach 42.4 percent, which was an increase in mean value of 19.4 percent $(3.04 \rightarrow 3.63)$. Innovative culture had the highest likelihood of increasing reward and recognition. The "what-if" analysis indicates that supporting an innovative culture would considerably increase employee perceptions of reward and recognition.

An innovative culture places great value on empowering employees to seek opportunities to experiment and create new ideas, and reach their potential (Ireland, Kuratko, $\&$ Morris, 2006). An organisation with an innovative culture embraces change and innovation to improve its performance (O' Cass \& Viet Ngo, 2007; Wipulanusat, Panuwatwanich, \& Stewart, 2017b). An innovative culture signals to employees that their participation in innovative activities is valued, which is found to enhance employees ' perception of reward and recognition (Lee, Cayer, \& Lan, 2006; Wei, O'Neill, Lee, \& Zhou, 2013). An innovative culture 
can increase employee confidence in their organisation's performance and future. If agencies have a strong innovative culture, there is less need for innovative project supervision from leaders. This creates more time for leaders to focus on other strategic tasks (Podsakoff, MacKenzie, \& Bommer, 1996). Leaders who perceive reward and recognition as an end in itself and fail to create a strong innovative culture may not achieve their goals.

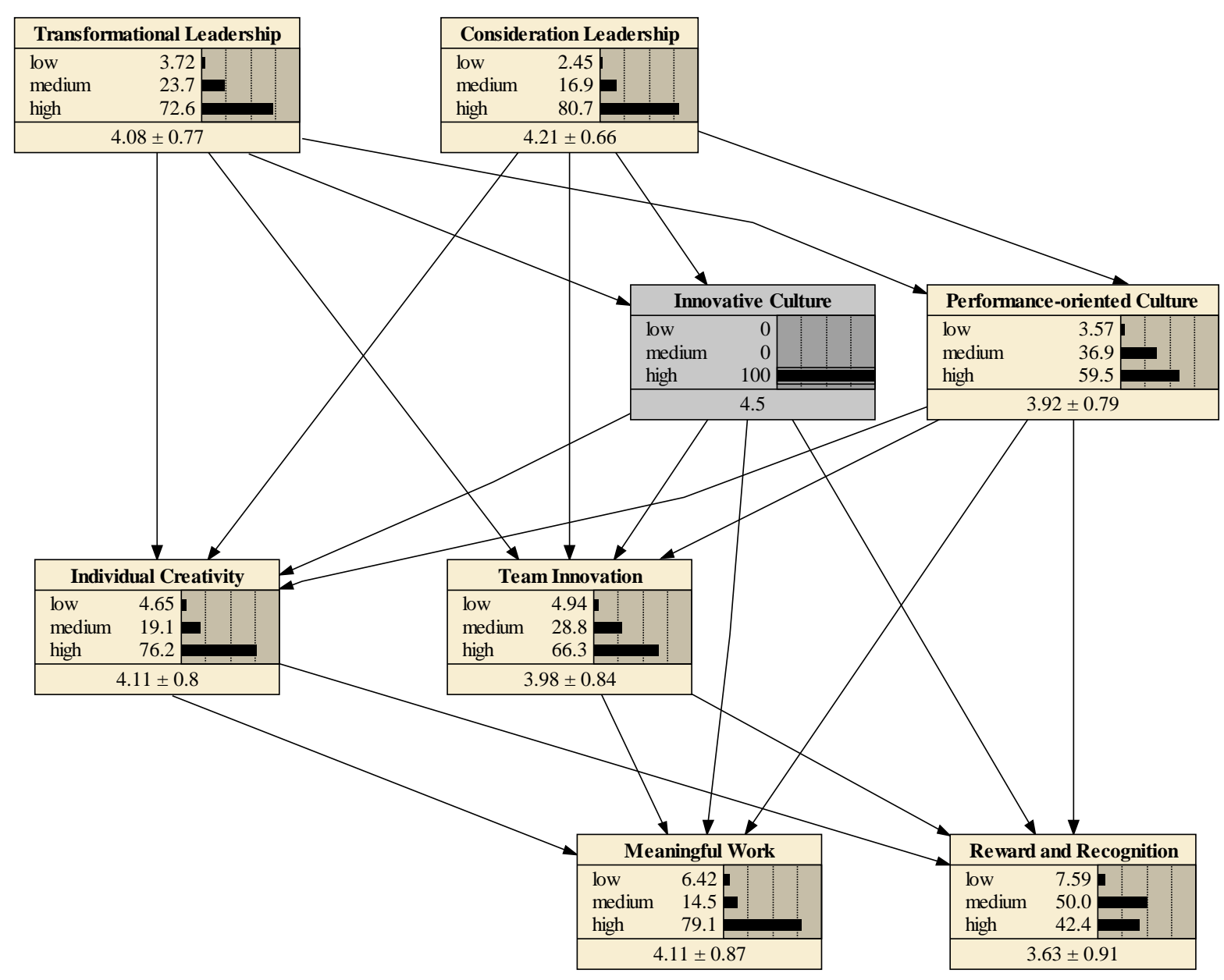

Figure 5. The effect of innovative culture

\subsubsection{Scenario 3: The effect of transformational leadership and innovative culture}

Another viable approach to improve reward and recognition is to promote more than one potential factor concurrently. However, improving the four factors within climate for innovation would require many obstacles to be overcome and could deplete resources before reaching the expected aims. Thus, it is recommended to integrate the two greatest explanatory factors highlighted by the sensitivity analysis for this scenario. This could be achieved by instantiating the high state for both transformational leadership and innovative culture to analyse their effects on increasing the likelihood of reward and recognition, as shown in Figure 
6. It was observed that reward and recognition had the highest variation on its mean value, increasing by 20.4 percent $(3.04 \rightarrow 3.66)$; however, this is still short of a high state. Thus, there is still considerable opportunity for further improvement to increase the perception of reward and recognition for engineers in the APS.

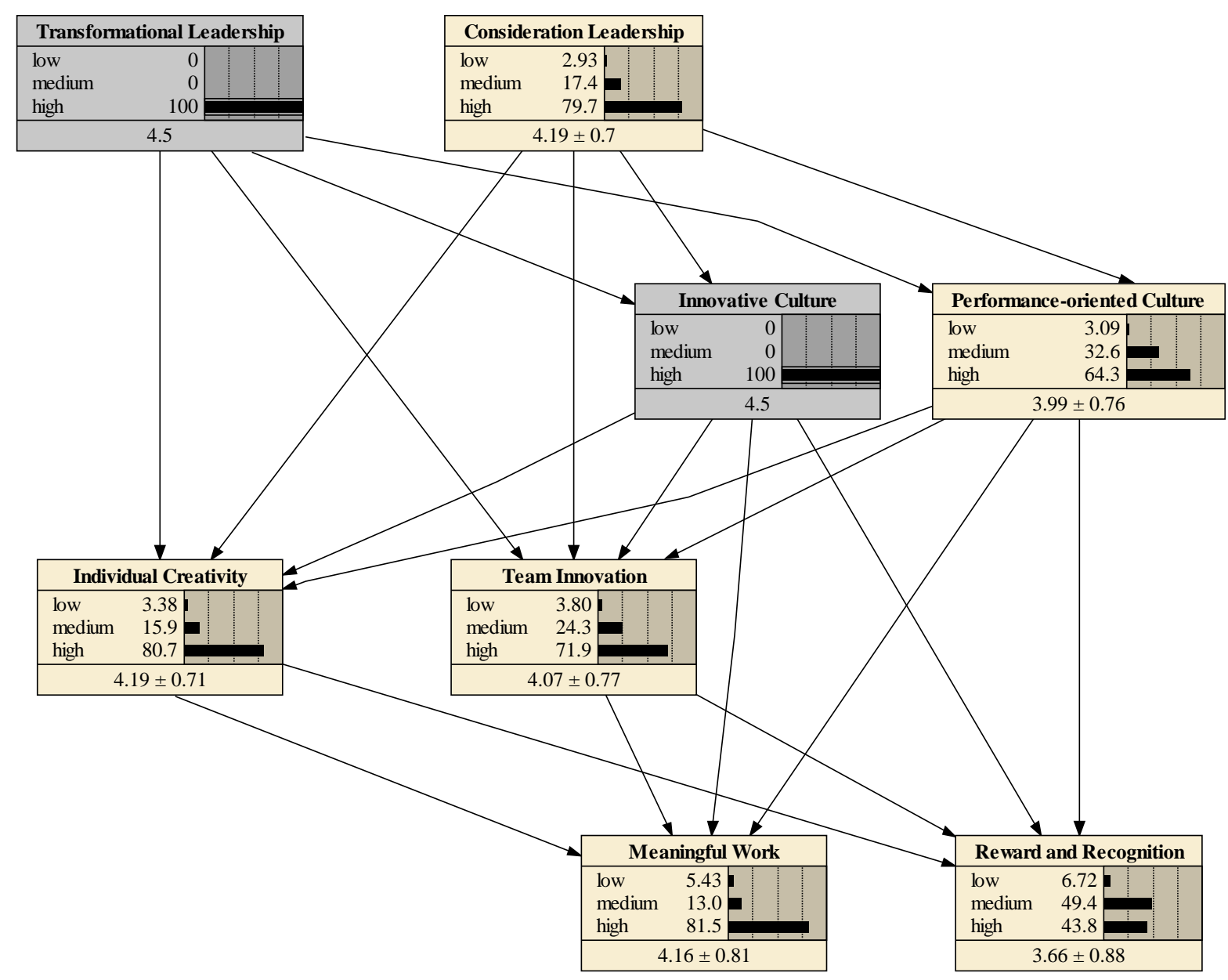

Figure 6. The effect of high transformational leadership and innovative culture

To improve perceptions of reward and recognition, leaders must practice transformational leadership and nurture innovative culture in their workplace. Transformational leadership in the federal government can have important direct and indirect effects on workplace innovation and career satisfaction (Oberfield, 2012; Trottier, Van Wart, \& Wang, 2008). An innovative culture thrives under a transformational leadership style that enhances trust (Carmeli \& Schaubroeck, 2007; Shin \& Zhou, 2007). Transformational leadership style is an important factor which significantly influences the successful delivery of innovative projects both directly and indirectly through an innovative culture (Gumusluoglu \& Ilsev, 2009; Kissi et al., 2012). 
A high innovative culture increases employee receptivity to an articulated vision and facilitates openness and responsiveness to change (Pawar \& Eastman, 1997). A strong innovative culture helps transformational leaders foster employee willingness and efforts towards innovation (Chen et al., 2012). When leaders can communicate the value of innovation to employees and create a strong employee perception toward the firm's innovative culture, such value and culture can improve employee satisfaction.

\subsubsection{Scenario 4: Maximise perceptions of reward and recognition}

As presented in Figure 7, the backward inference was conducted by instantiating the high state for the reward and recognition node. Compared to the current organisational situation, it can be observed that there is a significant change in the probabilities of innovative culture where a major chance of a high level of posterior probability occurs (55.4 percent). In order to maximise the perception of reward and recognition, this "goal seeking" analysis reveals that innovative culture needs to be improved from its baseline level of a medium state to a high state level.

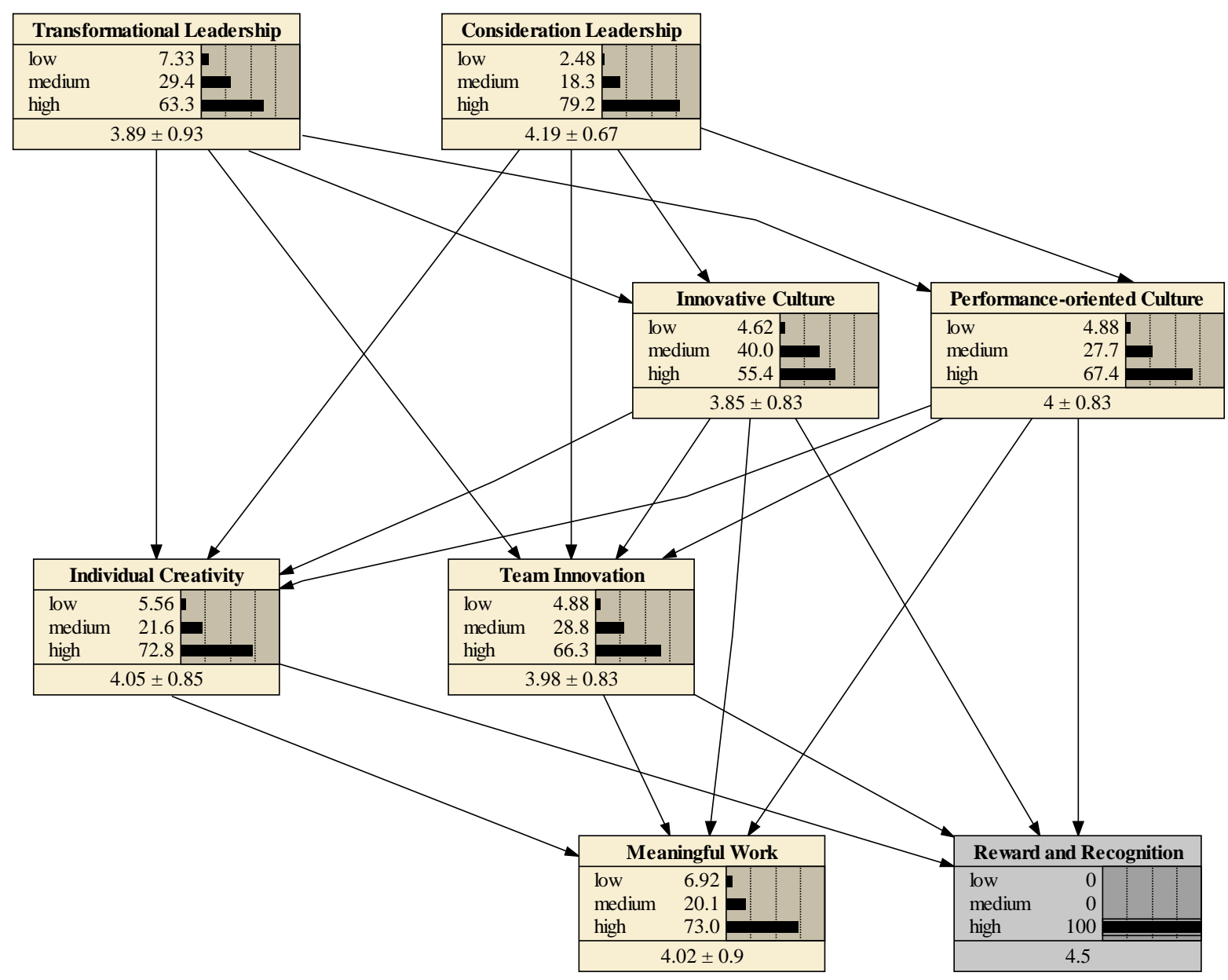

Figure 7. Maximise perceptions of reward and recognition 
Table 5. Prior and posterior mean value for each factor

\begin{tabular}{|c|c|c|c|}
\hline \multirow{2}{*}{ Factor } & \multicolumn{2}{|c|}{ Mean value } & \multirow{2}{*}{ Change rate $(\%)$} \\
\hline & Prior & Posterior & \\
\hline Transformation leadership & 3.57 & 3.89 & 8.96 \\
\hline Consideration leadership & 4.12 & 4.19 & 1.70 \\
\hline Innovative culture & 3.18 & 3.85 & 21.07 \\
\hline Performance-oriented culture & 3.82 & 4.00 & 4.71 \\
\hline Individual Creativity & 3.76 & 4.05 & 7.71 \\
\hline Team Innovation & 3.79 & 3.98 & 5.01 \\
\hline Meaningful Work & 3.79 & 4.02 & 6.07 \\
\hline
\end{tabular}

As presented in Table 5, the prior and posterior mean values of each factor were compared to consider their change rates. It can be observed that the posterior mean value of innovative culture has the highest change rate (21.07 percent). This is consistent with the sensitivity analysis which shows that the reward and recognition node was impacted primarily by innovative culture. The factor that has the second major influence is transformational leadership with a change rate of 8.96 percent. Therefore, transformational leadership directly impacts innovative culture and indirectly influences reward and recognition. To efficiently achieve reward and recognition, the first priority should be to instil an innovative culture in the organisation. A second and complementary option would be to support managers to practice and develop a transformational leadership style in their workplace. It is important to note that reward and recognition is not significantly impacted by consideration leadership and performance-oriented culture.

\section{Conclusions}

Although SEM and BN have been widely applied individually in many research studies, few of these studies have linked both techniques in order to identify causal relationships and aid decision support functions. This study applies a theoretically based and empirically validated model from SEM to develop a factor-level BN. The study sought to improve current understanding of the innovation process within the APS. The BN was performed to assess and refine causal relationships between the factors identified in the empirical SEM model. It revealed critical insights into the specific mechanisms to enhance individual creativity, as well as reward and recognition within the APS.

A sensitivity analysis was conducted to identify which critical factor had the greatest influence on the target node. Transformational leadership was found to be the key factor to 
instil individual creativity. The most significant factor affecting reward and recognition was innovative culture. After identifying these critical factors, a scenario analysis was essential to develop policy tools for decision-makers and formulate strategies to improve the innovation process in the APS. The BN was used for scenario-based simulations to conduct "what-if" and "goal-seeking" analyses. The importance of innovative culture was reaffirmed as the most influential factor on reward and recognition, as shown in the "what-if" analysis. Moreover, reward and recognition was best accomplished when efforts were combined to develop transformational leadership and instil an innovative culture. The "goal-seeking" analysis showed that if the ultimate organisational goal is to optimise reward and recognition, then the first priority should be to instil innovative culture in the organisation. A second, and complementary, option would be to support managers to practice and develop transformational leadership in their workplace. It is important to note that reward and recognition was not significantly impacted by consideration leadership or performance-oriented culture.

Researchers can benefit from integrating the strengths of SEM and BN. SEM provided an empirically validated model based on theoretical considerations, which was appropriate as a basis to develop a causal map. The BN was performed to assess and refine causal relationships between the factors identified in the empirical model. The BN was then applied for scenario analysis, which converted knowledge from the theoretical model into managerial actions.

\section{Implications}

There are two sets of implications from this study. Firstly, if organisations wish to encourage innovation among employees, they need to promote an innovative culture.

One way to promote a culture of innovation is through deliberate knowledge sharing (Mura, Lettieri, Radaelli, \& Spiller, 2013). This involves organisational practices for the exchange of information and sharing ideas and suggestions, both within teams and across team or departmental boundaries (Elrehail, Emeagwali, Alsaad, \& Alzghoul, 2018). When such practices are encouraged among employees, groups, and within the organisation as a whole, they lead to the generation of new ideas that are useful for developing new business opportunities (Heffner \& Sharif, 2008; Lundvall \& Nielsen, 2007).

Within organisations, the implementation of "slack innovation programs" can stimulate creativity (Rahrovani, Pinsonneault, \& Austin, 2018). To do this, organisations must provide time, technology and resources for individuals or teams to work on creative ideas and turn them 
into innovative products. Among private sector firms, Google's "20\% rule," which allows employees to work with anyone they choose on new ideas for $20 \%$ of their working hours, reportedly led to the development of Gmail, AdSense, and Google Earth. However, Rahrovani et al. (2018) claim that such programs work best for employees who are experts in their job area and who see themselves as innovative. It is important to identify these employees and allow them the freedom and resources to be innovative.

In public service organisations, the pressure to be accountable for resource use (Glor, 2014) would make it difficult to employ slack resource programs. However, it is still possible to empower employees to identify problems in current processes and suggest their own solutions to these problems. This is especially the case for service delivery where managers can support and reward employees for improvements they make (Fernandez \& Moldogaziev, 2013). The current research shows that reward and recognition are influenced by high levels of innovative culture.

A second major implication of this study is that if organisations wish to promote an innovative culture and encourage creativity among employees, they need to promote the use of transformational leadership at all levels of the organisation. Transformational leadership is enacted through a set of behaviours, which are said to be assessable and learnable (Bass \& Riggio, 2006; Parry \& Sinha, 2005).

As well as selecting transformational leaders as much as possible, organisations could look to use developmental approaches for existing managers who are judged to have leadership potential. Although there is often cynicism around the effectiveness of leadership training programs, Kelloway and Barling (2000) argued that if training focused on producing small, sustainable changes in leaders' behaviour then this would impact on subordinates more effectively. They believe the key to successful training programs is having the leaders develop concrete action plans with challenging, specific and achievable goals.

Others have pointed out the importance of combining structured training with 360degree feedback and coaching or mentoring (Day, Fleenor, Atwater, Sturm, \& McKee, 2014). The term "360-degree feedback" means that feedback comes from multiple sources (e.g., subordinates, peers, superiors, clients, suppliers, other stakeholders) who can assess a leader's behaviour based on their own interactions with the leader (Atwater \& Waldman, 1998). These people provide confidential ratings on the degree to which the leader demonstrates the behaviours expected for transformational leaders. The results are fed back to the leader by a 
leadership or executive coach who then helps the leader to set goals for improving in the areas they were rated poorly. On-going coaching or mentoring (ideally across several months) then supports the leader to gradually change their behaviours (Kelloway \& Barling, 2000).

The Multifactor Leadership Questionnaire (MLQ) is an instrument that is commonly used to assess transformational leadership (Bass \& Bass, 2009). It allows assessment of what is known as the "Full Range Leadership" (FRL) model: Five dimensions of leadership behaviours that fall under either transactional (day-to-day leadership that focuses on managing and rewarding performance) or transformational leadership (future-oriented leadership that inspires followers to give their best).

As the present study found that perceptions of reward and recognition occur when there is both transformational leadership and an innovative culture, it is recommended that strategies to improve both should be used together.

Although the scope of this paper is limited to engineers in federal departments and the results are restricted to the strategies regarding innovation and career satisfaction within the APS, the results of the findings and the insights are crucial and can be applicable to wider contexts. To further improve on the present research, future studies could be conducted to broaden the scope to state and local government levels. Federal Government heavily regulates state and local governments. Thus, engineering tasks are more structured and rule oriented. The future work should study which factors are important for engineers to develop innovation in the state and local governments under legislative constraint from the Federal Government. For the methodology, future research may also compare prediction outcomes of the BN with backpropagation neural networks (BPN) or classification and regression trees (CART). This comparison study could help to discover network architecture with the most accurate prediction.

\section{Acknowledgement}

This research did not receive any specific grant from funding agencies in the public, commercial, or not-for-profit sectors.

\section{Disclosure statement}

No potential conflict of interest was reported by the author(s). 


\section{ORCID}

Warit Wipulanusat (D) http://orcid.org/0000-0003-1006-6540

Kriengsak Panuwatwanich (D) http://orcid.org/0000-0002-6303-9485

Rodney A. Stewart (D) http://orcid.org/0000-0002-6013-3505

Stewart L. Arnold (iD http://orcid.org/0000-0003-3039-3418

Jue Wang (D) http://orcid.org/0000-0002-3401-713X

\section{Reference}

Amabile, T. M. (1988). A model of creativity and innovation in organizations. Research in Organizational Behavior, 10(1), 123-167.

Amabile, T. M., Schatzel, E. A., Moneta, G. B., \& Kramer, S. J. (2004). Leader behaviors and the work environment for creativity: Perceived leader support. The Leadership Quarterly, 15(1), 5-32.

Anderson, N., Potočnik, K., \& Zhou, J. (2014). Innovation and creativity in organizations: A state-of-the-science review, prospective commentary, and guiding framework. Journal of Management, 40(5), 1297-1333.

Anderson, R. D., Mackoy, R. D., Thompson, V. B., \& Harrell, G. (2004). A Bayesian network estimation of the service-profit chain for transport service satisfaction. Decision Sciences, 35(4), 665-689.

Anderson, R. D., \& Vastag, G. (2004). Causal modeling alternatives in operations research: Overview and application. European Journal of Operational Research, 156(1), 92-109.

Atwater, L., \& Waldman, D. (1998). 360 Degree feedback and leadership development. The Leadership Quarterly, 9(4), 423-426.

Bason, C. (2010). Leading public sector innovation: Co-creating for a better society. Bristol, UK: Bristol University Press.

Bass, B. M., \& Bass, R. (2009). The Bass handbook of leadership: Theory, research, and managerial applications. New York, NY: Simon and Schuster.

Bass, B. M., \& Riggio, R. E. (2006). Transformational leadership (2nd ed.). New Jersey, NJ: Psychology Press.

Bekkers, V. J., \& Homburg, V. (2005). The information ecology of e-government: egovernment as institutional and technological innovation in public administration. Amsterdam: IOS Press.

Benner, M. J., \& Tushman, M. L. (2003). Exploitation, exploration, and process management: The productivity dilemma revisited. Academy of Management Review, 28(2), 238-256.

Bertone, E., Sahin, O., Stewart, R. A., Zou, P. X. W., Alam, M., Hampson, K., \& Blair, E. (2018). Role of financial mechanisms for accelerating the rate of water and energy efficiency retrofits in Australian public buildings: Hybrid Bayesian Network and System Dynamics modelling approach. Applied Energy, 210, 409-419.

Bledow, R., Frese, M., Anderson, N., Erez, M., \& Farr, J. (2009). A dialectic perspective on innovation: Conflicting demands, multiple pathways, and ambidexterity. Industrial and Organizational Psychology, 2(3), 305-337. 
Boehmke, B. C., Johnson, A. W., White, E. D., Weir, J. D., \& Gallagher, M. A. (2016). Toothto-tail impact analysis: Combining econometric modeling and Bayesian networks to assess support cost consequences due to changes in force structure. Journal of Cost Analysis and Parametrics, 9(1), 2-31.

Borins, S. (2002). Leadership and innovation in the public sector. Leadership \& Organization Development Journal, 23(8), 467-476.

Borins, S. (2006). The challenge of innovation in government: Endowment for the business of government. Arlington, VA: PricewaterhouseCoopers.

Brandmayr, C., Kerber, H., Winker, M., \& Schramm, E. (2015). Impact assessment of emission management strategies of the pharmaceuticals Metformin and Metoprolol to the aquatic environment using Bayesian networks. Science of The Total Environment, 532(Supplement C), 605-616.

Cardenas, I. C., Voordijk, H., \& Dewulf, G. (2017). Beyond theory: Towards a probabilistic causation model to support project governance in infrastructure projects. International Journal of Project Management, 35(3), 432-450.

Carmeli, A., \& Schaubroeck, J. (2007). The influence of leaders' and other referents' normative expectations on individual involvement in creative work. The Leadership Quarterly, $18(1), 35-48$.

Chan, I. Y. S., Liu, A. M. M., \& Fellows, R. (2014). Role of leadership in fostering an innovation climate in construction firms. Journal of Management in Engineering, 30(6), $1-7$.

Chanda, U., \& Goyal, P. (2019). A Bayesian network model on the interlinkage between Socially Responsible HRM, employee satisfaction, employee commitment and organizational performance. Journal of Management Analytics, 1-34.

Chen, M. Y.-C., Lin, C. Y.-Y., Lin, H.-E., \& McDonough, E. F. (2012). Does transformational leadership facilitate technological innovation? The moderating roles of innovative culture and incentive compensation. Asia Pacific Journal of Management, 29(2), 239264.

Chen, S. H., \& Pollino, C. A. (2012). Good practice in Bayesian network modelling. Environmental Modelling \& Software, 37(Supplement C), 134-145.

Cinicioglu, E. N., Önsel, Ş., \& Ülengin, F. (2012). Competitiveness analysis of automotive industry in Turkey using Bayesian networks. Expert Systems with Applications, 39(12), 10923-10932.

Damanpour, F., \& Schneider, M. (2009). Characteristics of innovation and innovation adoption in public organizations: Assessing the role of managers. Journal of Public Administration Research and Theory: J-PART, 19(3), 495-522.

Damanpour, F., \& Wischnevsky, J. D. (2006). Research on innovation in organizations: Distinguishing innovation-generating from innovation-adopting organizations. Journal of Engineering and Technology Management, 23(4), 269-291.

Day, D. V., Fleenor, J. W., Atwater, L. E., Sturm, R. E., \& McKee, R. A. (2014). Advances in leader and leadership development: A review of 25 years of research and theory. The Leadership Quarterly, 25(1), 63-82.

De Jong, J. P., \& Den Hartog, D. N. (2007). How leaders influence employees' innovative behaviour. European Journal of innovation management, 10(1), 41-64. 
de Oliveira, M. A., Possamai, O., Dalla Valentina, L. V. O., \& Flesch, C. A. (2012). Applying Bayesian networks to performance forecast of innovation projects: A case study of transformational leadership influence in organizations oriented by projects. Expert Systems with Applications, 39(5), 5061-5070.

De Vries, H., Bekkers, V., \& Tummers, L. (2016). Innovation in the public sector: A systematic review and future research agenda. Public Administration, 94(1), 146-166.

Demircioglu, M. A., \& Audretsch, D. B. (2017). Conditions for innovation in public sector organizations. Research Policy, 46(9), 1681-1691.

Dwivedi, Y. K., Shareef, M., Pandey, S. K., \& Kumar, V. (2013). Public administration reformation: Market demand from public organizations (Vol. 18): Routledge.

Ekici, A., \& Ekici, S. O. (2016). A Bayesian network analysis of ethical behavior. Journal of Macromarketing, 36(1), 96-115.

Elrehail, H., Emeagwali, O. L., Alsaad, A., \& Alzghoul, A. (2018). The impact of transformational and authentic leadership on innovation in higher education: The contingent role of knowledge sharing. Telematics and Informatics, 35(1), 55-67.

Fernandez, S., \& Moldogaziev, T. (2013). Using employee empowerment to encourage innovative behavior in the public sector. Journal of Public Administration Research and Theory, 23(1), 155-187.

Fuster-Parra, P., García-Mas, A., Ponseti, F. J., Palou, P., \& Cruz, J. (2014). A Bayesian network to discover relationships between negative features in sport: a case study of teen players. Quality \& Quantity, 48(3), 1473-1491.

García-Morales, V. J., Jiménez-Barrionuevo, M. M., \& Gutiérrez-Gutiérrez, L. (2012). Transformational leadership influence on organizational performance through organizational learning and innovation. Journal of Business Research, 65(7), 10401050 .

Gil-Garcia, J. R., Helbig, N., \& Ojo, A. (2014). Being smart: Emerging technologies and innovation in the public sector. Government Information Quarterly, 31, I1-I8.

Glor, E. D. (2014). Studying the impact of innovation on organizations, organizational populations and organizational communities: A framework for research. The Innovation Journal: The Public Sector Innovation Journal, 19(3), 1.

Golembiewski, R. T., \& Vigoda, E. (2000). Organizational innovation and the science/craft of management. Current Topics in Management, 5, 263-280.

Gumusluoglu, L., \& Ilsev, A. (2009). Transformational leadership, creativity, and organizational innovation. Journal of Business Research, 62(4), 461-473.

Gupta, S., \& Kim, H. W. (2008). Linking structural equation modeling to Bayesian networks: Decision support for customer retention in virtual communities. European Journal of Operational Research, 190(3), 818-833.

Hahn, M. H., Lee, K. C., \& Jo, N. Y. (2015). Scenario-based management of individual creativity. Computers in Human Behavior, 42(Supplement C), 36-46.

Heffner, M., \& Sharif, N. (2008). Knowledge fusion for technological innovation in organizations. Journal of Knowledge Management, 12(2), 79-93.

Heslin, P. A. (2005). Conceptualizing and evaluating career success. Journal of Organizational Behavior, 26(2), 113-136. 
Ireland, R. D., Kuratko, D. F., \& Morris, M. H. (2006). A health audit for corporate entrepreneurship: innovation at all levels: part I. Journal of Business Strategy, 27(1), $10-17$.

Joo, B. K., \& Park, S. (2010). Career satisfaction, organizational commitment, and turnover intention: The effects of goal orientation, organizational learning culture and developmental feedback. Leadership \& Organization Development Journal, 31(6), 482500 .

Kayakutlu, G., Daim, T., Kunt, M., Altay, A., \& Suharto, Y. (2017). Scenarios for regional waste management. Renewable and Sustainable Energy Reviews, 74(Supplement C), 1323-1335.

Kelloway, E., \& Barling, J. (2000). What we have learned about developing transformational leaders. Leadership \& Organization Development Journal, 21(7), 355-362.

Kim, S., Eun , \& Chang, G. W. (2009). An empirical analysis of innovativeness in government: Findings and implications. International Review of Administrative Sciences, 75(2), 293310.

Kim, T.-Y., Hon, A. H. Y., \& Crant, J. M. (2009). Proactive personality, employee creativity, and newcomer outcomes: A longitudinal study. Journal of Business and Psychology, 24(1), 93-103.

Kissi, J., Dainty, A., \& Liu, A. (2012). Examining middle managers' influence on innovation in construction professional services firms: A tale of three innovations. Construction Innovation, 12(1), 11-28.

Kragt, M. E. (2009). A beginners guide to Bayesian network modelling for integrated catchment management. Canberra: Landscape Logic.

Laskey, K. B. (1995). Sensitivity analysis for probability assessments in Bayesian networks. IEEE Transactions on Systems, Man, and Cybernetics, 25(6), 901-909.

Lee, H., Cayer, N. J., \& Lan, G. Z. (2006). Changing federal government employee attitudes since the civil service reform act of 1978. Review of Public Personnel Administration, 26(1), 21-51.

Lundvall, B. A., \& Nielsen, P. (2007). Knowledge management and innovation performance. International Journal of Manpower, 28(3/4), 207-223.

Marcot, B. G. (2012). Metrics for evaluating performance and uncertainty of Bayesian network models. Ecological Modelling, 230, 50-62.

McAdam, R., Moffett, S., Hazlett, S. A., \& Shevlin, M. (2010). Developing a model of innovation implementation for UK SMEs: A path analysis and explanatory case analysis. International Small Business Journal, 28(3), 195-214.

McBurney, P., \& Parsons, S. (2003). Chance discovery and scenario analysis. New Generation Computing, 21(1), 13-22.

McMurray, A. J., Islam, M. M., Sarros, J. C., \& Pirola-Merlo, A. (2013). Workplace innovation in a nonprofit organization. Nonprofit Management and Leadership, 23(3), 367-388.

Mohammadfam, I., Ghasemi, F., Kalatpour, O., \& Moghimbeigi, A. (2017). Constructing a Bayesian network model for improving safety behavior of employees at workplaces. Applied Ergonomics, 58, 35-47.

Mulgan, G., \& Albury, D. (2003). Innovation in the public sector. London: Cabinet office. 
Mura, M., Lettieri, E., Radaelli, G., \& Spiller, N. (2013). Promoting professionals' innovative behaviour through knowledge sharing: the moderating role of social capital. Journal of Knowledge Management, 17(4), 527-544.

Ng, T. W. H., Eby, L. T., Sorensen, K. L., \& Feldman, D. C. (2005). Predictors of objective and subjective career success: a meta-analysis. Personnel Psychology, 58(2), 367-408.

Niedermayer, D. (2008). An Introduction to Bayesian Networks and Their Contemporary Applications. In D. E. Holmes \& L. C. Jain (Eds.), Innovations in Bayesian Networks: Theory and Applications (pp. 117-130). Berlin, Heidelberg: Springer Berlin Heidelberg.

Norsys Software Corp. (2010). Netica-J Reference Manual. Vancouver, Canada: Norsys.

Nusair, N., Ababneh, R., \& Bae, Y. K. (2012). The impact of transformational leadership style on innovation as perceived by public employees in Jordan. International Journal of Commerce and Management, 22(3), 182-201.

O' Cass, A., \& Viet Ngo, L. (2007). Market orientation versus innovative culture: two routes to superior brand performance. European Journal of Marketing, 41(7/8), 868-887.

Oberfield, Z. W. (2012). Public management in time: A longitudinal examination of the full range of leadership theory. Journal of Public Administration Research and Theory.

Panuwatwanich, K., Stewart, R. A., \& Mohamed, S. (2009). Critical pathways to enhanced innovation diffusion and business performance in Australian design firms. Automation in Construction, 18(6), 790-797.

Parry, K. W., \& Sinha, P. N. (2005). Researching the trainability of transformational organizational leadership. Human Resource Development International, 8(2), 165-183.

Pawar, B. S., \& Eastman, K. K. (1997). The nature and implications of contextual influences on transformational leadership: A conceptual examination. Academy of Management Review, 22(1), 80-109.

Pearl, J. (1998). Graphs, causality, and structural equation models. Sociological Methods \& Research, 27(2), 226-284.

Podsakoff, P. M., MacKenzie, S. B., \& Bommer, W. H. (1996). Transformational leader behaviors and substitutes for leadership as determinants of employee satisfaction, commitment, trust, and organizational citizenship behaviors. Journal of Management, 22(2), 259-298.

Pollitt, C., \& Bouckaert, G. (2011). Public Management Reform: A Comparative Analysis New Public Management, Governance, and the Neo-Weberian State (3rd ed.): Oxford University Press, USA.

Rahrovani, Y., Pinsonneault, A., \& Austin, R. D. (2018). If you cut employees some slack, will they innovate? MIT Sloan Management Review, 59(4), 47-51.

Rudd, L., Hajkowicz, S., Boughen, N., Nepal, S., \& Reeson, A. (2015). Fastforward: Scenarios for Queensland in the year 2025 describing the marketplace for education, healthcare, policing, transport and other public services. A CSIRO consultancy report for the Queensland Government Department of Science, Information Technology and Innovation. CSIRO, Australia.

Sharma, S. K., \& Chanda, U. (2017). Developing a Bayesian belief network model for prediction of R\&D project success. Journal of Management Analytics, 4(3), 321-344. 
Shin, S. J., \& Zhou, J. (2007). When is educational specialization heterogeneity related to creativity in research and development teams? Transformational leadership as a moderator. Journal of Applied Psychology, 92(6), 1709-1721.

Stogdill, R. M. (1950). Leadership, membership and organization. Psychological Bulletin, 47(1), 1-14.

Sturlaugson, L., \& Sheppard, J. W. (2015). Sensitivity analysis of continuous time Bayesian network reliability models. SIAM/ASA Journal on Uncertainty Quantification, 3(1), 346-369.

Sullivan, S. E., \& Baruch, Y. (2009). Advances in career theory and research: A critical review and agenda for future exploration. Journal of Management, 35(6), 1542-1571.

Ticehurst, J. L., Curtis, A., \& Merritt, W. S. (2011). Using Bayesian networks to complement conventional analyses to explore landholder management of native vegetation. Environmental Modelling \& Software, 26(1), 52-65.

Totterdill, P., \& Exton, R. (2014). Defining workplace innovation. Strategic Direction, 30(9), 12-16.

Trottier, T., Van Wart, M., \& Wang, X. (2008). Examining the nature and significance of leadership in government organizations. Public Administration Review, 68(2), 319-333.

Ülengin, F., Önsel, Ş., Aktas, E., Kabak, Ö., \& Özaydın, Ö. (2014). A decision support methodology to enhance the competitiveness of the Turkish automotive industry. European Journal of Operational Research, 234(3), 789-801.

Wei, Y., O'Neill, H., Lee, R. P., \& Zhou, N. (2013). The impact of innovative culture on individual employees: The moderating role of market information sharing. Journal of Product Innovation Management, 30(5), 1027-1041.

Wilkinson, A., \& Kupers, R. (2013). Living in the futures. Harvard Business Review, 91(5), 118-127.

Wipulanusat, W., Panuwatwanich, K., \& Stewart, R. A. (2017a). Exploring leadership styles for innovation: an exploratory factor analysis. Engineering Management in Production and Services, 9(1), 7-17.

Wipulanusat, W., Panuwatwanich, K., \& Stewart, R. A. (2017b). Statistical data analysis of culture for innovation using an open data set from the Australian Public Service. Lecture Notes in Computer Science, 10365, 78-89.

Wipulanusat, W., Panuwatwanich, K., \& Stewart, R. A. (2017c). Workplace innovation: Exploratory and confirmatory factor analysis for construct validation. Management and Production Engineering Review, 8(2), 57-68.

Wipulanusat, W., Panuwatwanich, K., \& Stewart, R. A. (2018). Pathways to workplace innovation and career satisfaction in the public service: The role of leadership and culture. International Journal of Organizational Analysis, 26(5), 890-914.

Wipulanusat, W., Panuwatwanich, K., Stewart, R. A., \& Sunkpho, J. (2019). Drivers and barriers to innovation in the Australian public service: a qualitative thematic analysis. Engineering Management in Production and Services, 11(1), 7-22.

Yang, K., \& Kassekert, A. (2010). Linking management reform with employee Job satisfaction: Evidence from federal agencies. Journal of Public Administration Research and Theory, 20(2), 413-436. 
Yang, Y., \& Xu, D.-L. (2017). A methodology for assessing the effect of portfolio management on NPD performance based on Bayesian network scenarios. Expert Systems, 34(2), 110.

Yukl, G. A. (2006). Leadership in organizations. Upper Saddle River, NJ: Prentice-Hall.

Zhou, J., \& Hoever, I. J. (2014). Research on workplace creativity: A review and redirection. Annual Review of Organizational Psychology and Organizational Behavior, 1(1), 333359. 